\title{
A prospective randomized study of the inflammatory responses to multiport and singleport laparoscopic hysterectomies $^{1}$
}

Renata Assef Tormena', Sérgio Conti Ribeiro", José Maria Soares Júnior"', Gustavo Arantes Rosa Maciel"I', Edmund Chada Baracat ${ }^{\text {IV }}$

'MD, Division of Gynecology, School of Medicine, Hospital das Clínicas, Universidade de São Paulo (USP), Brazil. Intellectual and scientific content of the study; conception and design of the study; acquisition, analysis and interpretation of data; technical procedures; statistics analysis; manuscript preparation and writing.

"PhD, Division of Gynecology, School of Medicine, Hospital das Clínicas, USP, Sao Paulo-SP, Brazil. Intellectual and scientific content of the study; conception and design of the study; acquisition, analysis and interpretation of data; technical procedures; statistics analysis; manuscript preparation and writing.

I'PhD, Division of Gynecology, School of Medicine, Hospital das Clínicas, USP, Sao Paulo-SP, Brazil. Critical revision, final approval.

IVPhD, Head, Division of Gynecology, School of Medicine, Hospital das Clínicas, USP, Sao Paulo-SP, Brasil. Critical revision, final approval.

\begin{abstract}
Purpose: To evaluate the inflammatory responses induced by laparoscopic hysterectomies with multiport and singleport approaches.

Methods: This was a pilot prospective randomized study that included 42 women candidates for hysterectomy at School of Medicine, Hospital das Clínicas, USP. The patients were randomized to two groups: MP-TLH (total laparoscopic hysterectomy with 3 abdominal incisions), and SP-TLH (total laparoscopic hysterectomy with a single umbilical incision). We evaluated the inflammatory response (via CRP, IL-6, IL-10, TNF $\alpha$, VEGF and leukogram assessments), surgical time, postoperative pain, blood loss and surgical complications in both groups.

Results: Both techniques were similar regarding C-reactive protein $(p=.666), I L-6(p=.833)$, IL-10 ( $p=.420)$, TNF- $\alpha(p=.098), \operatorname{VEGF}(p=.092)$ and the leukogram $(p=.712)$ measures. The operative time was significantly longer in the SP-TLH group than in the MP-TLH group $(p=.001)$. The pain evaluation was similar in both groups $(p=.170)$. Hemoglobin variation and the aspirated blood volume were similar in both groups $(p=.493$ and $p=.347)$. There were no major complications.

Conclusions: Multiport and singleport laparoscopic approaches are both safe methods for hysterectomy. Although SP-TLH resulted in a significantly longer operative time than MP-TLH, no differences were observed between the groups in inflammatory responses, blood loss and postoperative pain.
\end{abstract}

Key words: Hysterectomy. Laparoscopy. Singleport. 


\section{Introduction}

Surgical trauma activates neuroendocrine responses and consequently alters hemodynamic and metabolic statuses. Subsequent increases in the production of inflammatory cytokines occur, mainly IL-6 after operative injury. This cytokine activates a system for the subsequent production of acute phase proteins and increases C-reactive protein (CRP). The severities of the immune disorders are proportional to the extent of the surgical trauma ${ }^{1-3}$. In addition to the cytokines' actions on wound healing, the mobilization of macrophages is responsible for the production of growth factors, such as vascular endothelial growth factor (VEGF), which are essential for the development of surgical scars and granulation tissue ${ }^{4,5}$.

There are studies that have analyzed the inflammatory responses elicited by the surgical traumas associated with different surgical approaches for hysterectomies. They suggest that both vaginal or laparoscopic approach have superior results than abdominal hysterectomy ${ }^{6-9}$. One possible evolution of laparoscopy, i.e., singleport access, aims to further reduce the surgical morbidity and is associated with better cosmetic results ${ }^{10,11}$.

Some authors reported advantages of singleport laparoscopic hysterectomy compared to multiport laparoscopy, such as shorter recover period, lower incidence of infection, less postoperative pain and higher patient satisfaction scores after surgery. However, the singleport hysterectomy was usually a time-consuming procedure, longer than multiport technique ${ }^{11-18}$. However, a larger umbilical incision could facilitate closure of the fascia and eventually decreases herniation risk $^{10,19}$. These advantages of singleport surgery may reduce the surgical tissue trauma, providing better postoperative results compare to multiport laparoscopy.
A study that evaluates the inflammatory responses following laparoscopic multiport and singleport hysterectomies is still missing. The aim of the present prospective randomized trial is to compare the inflammatory response and surgical outcomes after singleport and multiport laparoscopic hysterectomies.

\section{Methods}

From March 2013 to June 2014, we performed a pilot study including 42 patients with benign gynecological diseases who were scheduled for hysterectomies at the São Paulo University Medical School Hospital. The Ethics Committee (CAPPesq-FMUSP) approved the protocol of this study (CAAE 20957813.5.0000.0008). After an informed consent was signed by each patient, we prospectively randomized these patients to eithermultiporttotallaparoscopichysterectomy (MP-TLH) or singleport hysterectomy (SP-TLH) using the Random Password Generator Bitmill ${ }^{\circ}$ Inc (Calgary, Canada). We did not include patients with coagulation disorders, those who used any anti-inflammatory agents within the previous 3 months, those with suspected uterine cancer, those with endometriosis or pelvic inflammatory disease, those with contraindications for general anesthesia, those with genital prolapse or those with uterine volumes greater than $600 \mathrm{~cm}^{3}$.

We previously reported the surgical outcomes of all patients (except one) allocated in the singleport group ${ }^{20}$. This study met the criteria of our Institutional Review Board, and the post-informed consent of all patients was obtained. We considered "surgical conversion" as the necessity for additional trocar insertion or even laparotomy in both groups.

Venous peripheral blood levels of CRP, IL-6, IL-10, TNF $\alpha$, VEGF and leukogram were measured to evaluated the surgical inflammatory responses. 
Blood samples were taken immediately before and after surgery, on the $1^{\text {st }}, 2^{\text {nd }}$ and $6^{\text {th }}$ postoperative days and placed into tubes containing EDTA.

The cytokines were measured using flow cytometry technique (Bio-Plex Pro ${ }^{\text {tm }}$ Human Inflammation Assays, USA), that are essentially immunoassays formatted on magnetic beads that enable to research multiple cytokines at the same time. Capture antibodies directed against the desired biomarker are covalently coupled to the beads, after a series of washes, a biotinylated detection antibody is added to create a sandwich complex. The CRP dosages were measured by imunoturbidimetric assay with intensification of particles' reaction, using the Roche/Hitachi Cobas C 502 system (Roche
Diagnostics, North America).

The dosages of hemoglobin were done by automatic analyzer (XT- 2000i SYSMEX) at the same moments that cytokines dosages. The patients were discharged on the $2^{\text {nd }}$ postoperative day (POD), and they were clinically evaluated on the $6^{\text {th }}$ day (POD), at six weeks, six months and one year after surgery. Additionally, postoperative pain intensity was estimated using a visual analog scale (VAS) ${ }^{21}$ on the $1^{\text {st }}, 2^{\text {nd }}$ and $6^{\text {th }}$ postoperative days. The patients' ages varied from 35 to 63 years, and the clinical characteristics of the patients are presented in Table 1 . This study was previously submitted and approved by Institution Review Board at Hospital das Clínicas, Universidade de São Paulo.

Table 1 - Clinical and inflammation markers (cytokines and leucocytes) data.

\begin{tabular}{|c|c|c|c|}
\hline Variable & $\begin{array}{l}\text { Group } \\
\text { multiport-TLH }(N=21)\end{array}$ & Singleport -TLH $(N=19)$ & $\mathbf{P}$ \\
\hline Age (years) & $46.71 \pm 5.43$ & $47.58 \pm 6.92$ & .661 \\
\hline Parity & $2.24 \pm 2.12$ & $3 \pm 1.41$ & .054 \\
\hline $\mathrm{BMI}\left(\mathrm{Kg} / \mathrm{m}^{2}\right)$ & $27.0 \pm 5.6$ & $27.3 \pm 3.2$ & .843 \\
\hline Uterine weight (g) & $227.6 \pm 143.5$ & $174.8 \pm 81.01$ & $.421 *$ \\
\hline Cesarean delivery & $1.1 \pm 1.22$ & $0.84 \pm 1.12$ & $.486^{*}$ \\
\hline Vaginal delivery & $1.14 \pm 2.13$ & $2.16 \pm 1.61$ & $.015^{*}$ \\
\hline CRP & & & .666 \\
\hline Pre-operative & $2.9 \pm 4.27$ & $2.21 \pm 1.98$ & \\
\hline PO Immediate & $2.27 \pm 3.65$ & $1.87 \pm 1.57$ & \\
\hline $10 \mathrm{PO}$ & $56.99 \pm 57.88$ & $58.44 \pm 59.43$ & \\
\hline $2 \div \mathrm{PO}$ & $78.31 \pm 86.21$ & $58.55 \pm 40.38$ & \\
\hline $60 \mathrm{PO}$ & $9.94 \pm 10.77$ & $50.31 \pm 102.47$ & \\
\hline VEGF & & & .092 \\
\hline Pre-operative & $8.19 \pm 6.94$ & $4.57 \pm 4.17$ & \\
\hline PO Immediate & $15 \pm 17.81$ & $5.84 \pm 7.31$ & \\
\hline $10 \mathrm{PO}$ & $17.97 \pm 27.76$ & $12.01 \pm 13.67$ & \\
\hline $2 \div \mathrm{PO}$ & $9.18 \pm 6.04$ & $7.27 \pm 6.97$ & \\
\hline $60 \mathrm{PO}$ & $12.43 \pm 10.38$ & $8.83 \pm 10.56$ & \\
\hline TNF-a & & & .098 \\
\hline Pre-operative & $4.22 \pm 3.57$ & $3.15 \pm 3.33$ & \\
\hline
\end{tabular}




\begin{tabular}{lll}
\hline PO Immediate & $3.92 \pm 4.05$ & $2.03 \pm 1.67$ \\
1o PO & $4.11 \pm 3.34$ & $3.23 \pm 1.95$ \\
2o PO & $4.17 \pm 3.52$ & $3.04 \pm 2.29$ \\
6o PO & $4.38 \pm 5.3$ & $3.18 \pm 2.49$ \\
IL-6 & & \\
Pre-operative & $1.55 \pm 1.38$ & $1.24 \pm 0.75$ \\
PO Immediate & $4.47 \pm 3.22$ & $4.21 \pm 2.44$ \\
1ㅇ PO & $6.57 \pm 7.3$ & $7.16 \pm 7.41$ \\
2o PO & $3.08 \pm 2.83$ & $2.1 \pm 0.93$ \\
6o PO & $2.36 \pm 2.27$ & $2.6 \pm 1.77$ \\
IL-10 & & \\
Pre-operative & $2.03 \pm 3.07$ & $1.44 \pm 2.94$ \\
PO Immediate & $2.1 \pm 1.57$ & $1.49 \pm 1.82$ \\
10 PO & $1.95 \pm 2.2$ & $1.71 \pm 1.94$ \\
2o PO & $1.96 \pm 2.91$ & $1.38 \pm 1.7$ \\
6o PO & $2.01 \pm 2.31$ & $1.52 \pm 1.86$ \\
Leucocytes & & \\
Pre-operative & $6.17 \pm 1.52$ & $6.33 \pm 1.78$ \\
PO Immediate & $8.98 \pm 4.26$ & $10.5 \pm 3.26$ \\
1ㅇ PO & $10.45 \pm 3.05$ & $9.88 \pm 2.42$ \\
2o PO & $7.59 \pm 2.02$ & $7.16 \pm 1.79$ \\
6o PO & $7.85 \pm 2.38$ & $8.2 \pm 2.02$ \\
\hline S & & .420 \\
\hline
\end{tabular}

Student'st-test; * Mann-Whitney test. BMI: body mass index; \pm standard deviation (SD). Generalized estimating equations. PO: postoperative; CRP: C-reactive protein; IL: interleukin; VEGF: vascular endothelia growth factor; TNF-alpha: tumor necrosis factor alpha

\section{Techniques}

\section{$\underline{\text { Singleport-TLH }}$}

Initially, a 2.5-cm trans-umbilical longitudinal incision was made until the aponeurosis was reached; this incision was opened and fixed with stitches in both sides. Next, the peritoneum was opened, and a disposable three-channel single-port device was inserted, i.e., either the Triport Access System $^{\circledR}$ (Olympus, Center Valley, PA) or the Single Site Laparoscopy (SSL) Access System (Ethicon Endo-Surgery, Somerville, NJ, USA). An intra-peritoneal pressure of $15 \mathrm{mmHg}$ was maintained. A $30^{\circ}$, a 5-mm obese telescope associated with conventional rigid laparoscopic instruments, including monopolar and bipolar forceps and Ultracision ${ }^{\circledR}$ (Ethicon EndoSurgery, Somerville, NJ, USA) was used. The Valtchev Uterine Manipulator ${ }^{\circledR}$ (Conkin, Canada) enables the complete range of uterine movements and facilitates access to different angles of the uterus.

Type IV-E laparoscopic hysterectomy according to the AAGL classification was performed as follows ${ }^{22}$. The utero-ovarian ligament, fallopian tube pedicles and the round ligaments were coagulated and divided with ultracision scissors. The vesicouterine peritoneal fold and bladder were mobilized off of the uterus and upper vagina until the anterior vagina was identified. The broad ligament peritoneum was divided, and the uterine artery was coagulated and 
divided with bipolar and ultracision scissors. The cardinal and uterosacral ligaments, one for each side, were divided. The vagina was entered posteriorly near the cervicovaginal junction. A 4-cm diameter plastic vaginal delineator was placed in the vagina to circumferentially outline the cervical junction and prevent the loss of the pneumoperitoneum. Monopolar forceps were used to complete the circumferential culdotomy. Although bilateral oophorectomy was performed only in select cases, bilateral salpingectomy was routinely performed. The specimens were pulled out of the vagina. The vaginal delineator was placed back into the vagina for the laparoscopic review of hemostasis and to delineate the vaginal cuff. Vaginal cuff closure was achieved either through the laparoscopic extracorporeal tie technique (5 patients) or vaginal (14 patients) access. Sutures (0-vicryl, Ethicon Endo-Surgery, Somerville, NJ, USA) were placed through the left and right uterosacral ligaments and through the posterior and anterior vaginal folds. In one patient, a barbed suture was used to perform this surgical step. The umbilical incision fascia was closed using 0-vicryl running sutures, and an intradermic suture was placed to end the procedure.

\section{Multiport-TLH}

Three laparoscopic puncture sites, including the umbilicus, were used, i.e.,11$\mathrm{mm}$ umbilical, 5-mm right, and 5-mm left lower quadrant sites. A $0^{\circ}, 10-\mathrm{mm}$ telescope associated with conventional rigid laparoscopic instruments, including monopolar and bipolar forceps and Ultracision ${ }^{\circledR}$ (Ethicon EndoSurgery, Somerville, NJ, USA) were used. The hysterectomies were also performed as type IV-E laparoscopic hysterectomies. Vaginal cuff closure was performed via the laparoscopic approach in all patients. The umbilical incisions of the fascia were closed using 0-vicryl with simple sutures, and an intradermic suture was placed to end the procedure.

\section{Statistical analysis}

Data were expressed as the mean, standard deviation, median, maximum or minimum, and the statistical significance was accepted at $p<0.05$. Either t-Student or Mann-Whitney test was applied to statistical evaluation between-groups differences in terms of personal characteristics. Inflammatorymarkers' levels and leucogram were analyzed between-groups and moments by repeated measures using generalized estimation equations with first order auto-regressive correlation matrix between the moments, with normal distribution and identity link function.

Repeated measurement post hoc between-groups and moments effects were evaluated by Bonferroni test. Bleeding and surgical time were described by groups and compared using Mann-Whitney test.

\section{Results}

\section{Primary outcomes: inflammatory markers}

The serum levels of CRP, IL- 6 and VEGF increased along with the evaluated moments. The IL- 6 and VEGF levels reached peak values at $1^{\text {stPOD }}$ and subsequently declined gradually however, there were no differences between the SP-TLH and MP-TLH groups $(p=.833$ and $p=.092$, respectively). Although there was an intense decrease in CRP on the sixth postoperative day in the MP-TLH group, there were no differences in the serum CRP levels between the treatment groups even at the sixth postoperative day $(p=666)$. All of the inflammatory markers are presented in Table1.

There were no significant increases in IL10 or TNF- $\alpha$ following the surgeries $(p=.961$ and $p=.247$, respectively) in either group $(p=.420$ and $p=.098$ ). There were significant increases in the leukocyte numbers after surgery $(p<.001)$ that were similar between both techniques $(p=.712)$. The inflammatory markers curves are presented in Figure 1. 

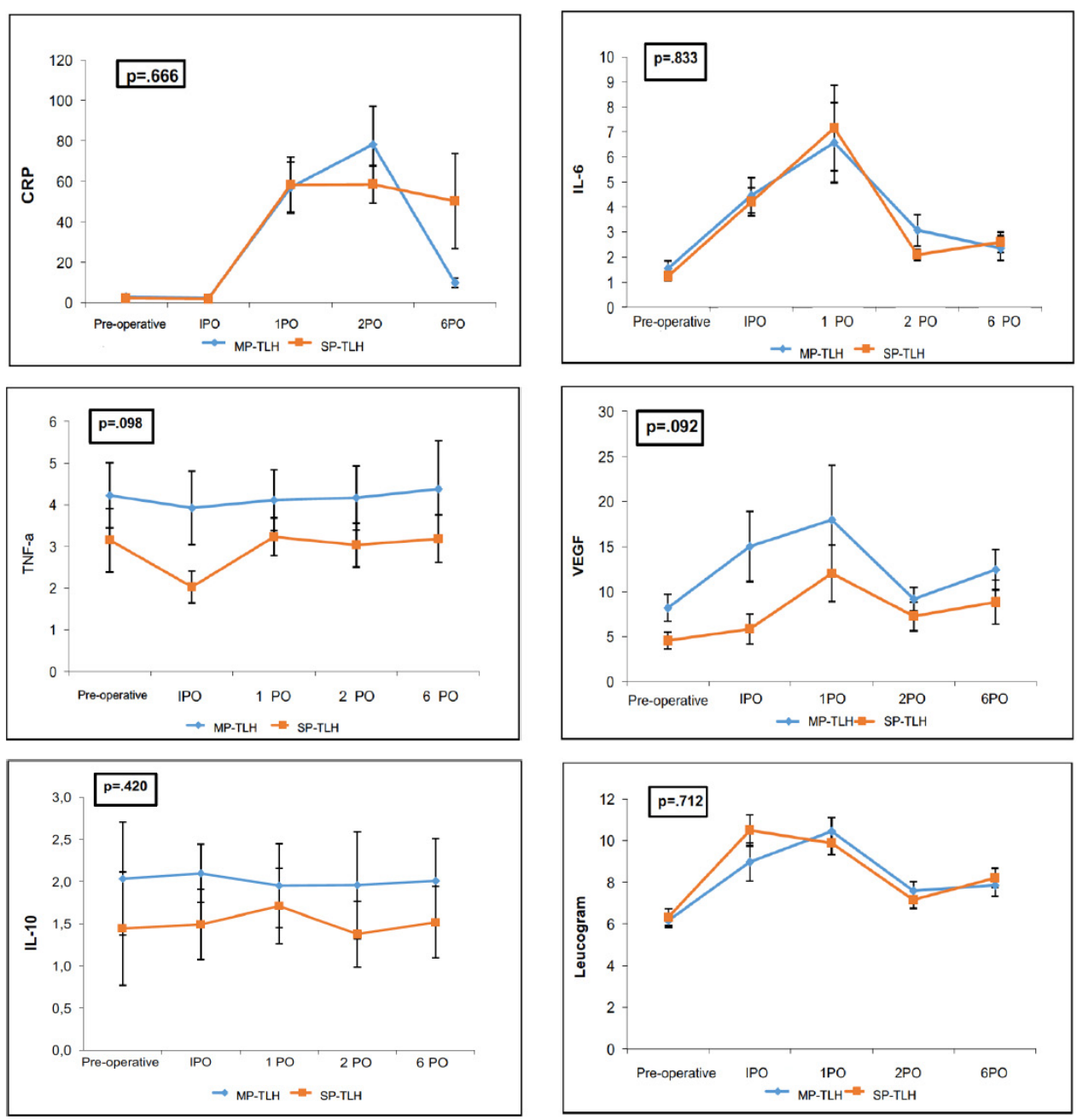

Figure 1 - IPO: immediate postoperative day; 1PO: first postoperative day; 2PO: second postoperative day; 6PO: sixth postoperative day; MP-TLH: multiport total laparoscopic hysterectomy; SP-TLH: singleport total laparoscopic hysterectomy; $\mathbf{p}$ : significance level.

\section{Secondary outcomes}

The SP-TLH operative time was significantly longer than that of the MPTLH approach (165.74 min. vs. 130.86 min., respectively, $p=.001)$. We inserted two additional suprapubic 5-mm trocars to safely complete the procedure in one patient with extensive pelvic adhesions who were initially scheduled to SP-TLH. This patient was excluded from the statistical analysis. One other patient in the same group did not return in $6^{\text {th }}$ POD visit and she was also excluded. There was no significant difference between the groups in relation of hemoglobin variation $(p=.493)$ and aspirated blood volume ( $p=.347)$, Table 2 . There were no blood transfusion and all patients were uneventfully discharged from the hospital within 48 hours after surgeries. The levels of postoperative pain were similar between the MP-TLH and SP-TLH groups ( $p=.170$, Table 3$)$. There was no difference between the $2^{\text {nd }}$ and $6^{\text {th }}$ day after surgery $(p=.721)$. There was no postoperative vaginal vault prolapse or urinary incontinence. However, 12 months after the surgeries, we identified three cases of umbilical hernias in the SP-TLH group. 
Table 2 - Cytokines and leucocytes.

\begin{tabular}{|c|c|c|c|}
\hline mean (sd) & $\begin{array}{l}\text { Group } \\
\text { MP-TLH } \\
(\mathbf{N}=\mathbf{2 1})\end{array}$ & $\begin{array}{l}\text { SP-TLH } \\
(\mathrm{N}=19)\end{array}$ & $\mathbf{p}$ \\
\hline CRP & & & .666 \\
\hline Pre-operative & $2.9 \pm 4.27$ & $2.21 \pm 1.98$ & \\
\hline PO Immediate & $2.27 \pm 3.65$ & $1.87 \pm 1.57$ & \\
\hline $10 \mathrm{PO}$ & $56.99 \pm 57.88$ & $58.44 \pm 59.43$ & \\
\hline $20 \mathrm{PO}$ & $78.31 \pm 86.21$ & $58.55 \pm 40.38$ & \\
\hline $60 \mathrm{PO}$ & $9.94 \pm 10.77$ & $50.31 \pm 102.47$ & \\
\hline VEGF & & & .092 \\
\hline Pre-operative & $8.19 \pm 6.94$ & $4.57 \pm 4.17$ & \\
\hline PO Immediate & $15 \pm 17.81$ & $5.84 \pm 7.31$ & \\
\hline 1으 PO & $17.97 \pm 27.76$ & $12.01 \pm 13.67$ & \\
\hline $2 \circ \mathrm{PO}$ & $9.18 \pm 6.04$ & $7.27 \pm 6.97$ & \\
\hline $60 \mathrm{PO}$ & $12.43 \pm 10.38$ & $8.83 \pm 10.56$ & \\
\hline TNF-a & & & .098 \\
\hline Pre-operative & $4.22 \pm 3.57$ & $3.15 \pm 3.33$ & \\
\hline PO Immediate & $3.92 \pm 4.05$ & $2.03 \pm 1.67$ & \\
\hline 1요 PO & $4.11 \pm 3.34$ & $3.23 \pm 1.95$ & \\
\hline $2 \div \mathrm{PO}$ & $4.17 \pm 3.52$ & $3.04 \pm 2.29$ & \\
\hline 60 PO & $4.38 \pm 5.3$ & $3.18 \pm 2.49$ & \\
\hline IL-6 & & & .833 \\
\hline Pre-operative & $1.55 \pm 1.38$ & $1.24 \pm 0.75$ & \\
\hline PO Immediate & $4.47 \pm 3.22$ & $4.21 \pm 2.44$ & \\
\hline 1요 PO & $6.57 \pm 7.3$ & $7.16 \pm 7.41$ & \\
\hline $2 \circ \mathrm{PO}$ & $3.08 \pm 2.83$ & $2.1 \pm 0.93$ & \\
\hline 60 PO & $2.36 \pm 2.27$ & $2.6 \pm 1.77$ & \\
\hline IL-10 & & & .420 \\
\hline Pre-operative & $2.03 \pm 3.07$ & $1.44 \pm 2.94$ & \\
\hline PO Immediate & $2.1 \pm 1.57$ & $1.49 \pm 1.82$ & \\
\hline 1요 PO & $1.95 \pm 2.2$ & $1.71 \pm 1.94$ & \\
\hline $2 \circ \mathrm{PO}$ & $1.96 \pm 2.91$ & $1.38 \pm 1.7$ & \\
\hline $60 \mathrm{PO}$ & $2.01 \pm 2.31$ & $1.52 \pm 1.86$ & \\
\hline Leucocytes & & & .712 \\
\hline Pre-operative & $6.17 \pm 1.52$ & $6.33 \pm 1.78$ & \\
\hline PO Immediate & $8.98 \pm 4.26$ & $10.5 \pm 3.26$ & \\
\hline 1요 PO & $10.45 \pm 3.05$ & $9.88 \pm 2.42$ & \\
\hline 2으 PO & $7.59 \pm 2.02$ & $7.16 \pm 1.79$ & \\
\hline 6 $\mathrm{PO}$ & $7.85 \pm 2.38$ & $8.2 \pm 2.02$ & \\
\hline
\end{tabular}

Generalized estimating equations. PO: postoperative; CRP: C-reactive protein; IL: interleukin; VEGF: vascular endothelia growth factor; TNF- $\alpha$ : tumor necrosis factor alpha. 
Table 3 - Surgical outcomes.

\begin{tabular}{|c|c|c|c|}
\hline & Group & & p \\
\hline Variable & MP-TLH & SP-TLH & \\
\hline (mean $\pm S D)$ & $(N=21)$ & $(N=19)$ & \\
\hline Pain & & & .170 \\
\hline $10 \mathrm{PO}$ & $3.81(2.36)$ & $4.42(2.71)$ & \\
\hline $2 \div \mathrm{PO}$ & $1.95(1.66)$ & $2.79(2.46)$ & \\
\hline $60 \mathrm{PO}$ & $2.43(2.52)$ & $2.84(2.48)$ & \\
\hline Operative time (min.) & $130.86(31.69)$ & $165.74(23.12)$ & $.001 *$ \\
\hline Hemoglobin variation $(\mathrm{g} / \mathrm{dl})$ & & & .493 \\
\hline Preoperative day & $13.00(1.55)$ & $13.02(1.24)$ & \\
\hline IPO & $11.87(1.57)$ & $11.80(1.12)$ & \\
\hline $10 \mathrm{PO}$ & $12.02(1.43)$ & $11.50(1.24)$ & \\
\hline $2 \circ \mathrm{PO}$ & $11.72(1.29)$ & $11.37(1.13)$ & \\
\hline $60 P O$ & $12.60(1.42)$ & $12.25(1.14)$ & \\
\hline Aspirated blood volume (ml) & $147.86(81.74)$ & $197.37(142.17)$ & $.347^{*}$ \\
\hline
\end{tabular}

Generalized estimating equations. * Mann-Whitney test. PO: postoperative; SD: standard deviation.

\section{- Discussion}

Laparoscopic hysterectomy is a good technique, and compared with other accesses, this technique has the same advantages of the vaginal approach, which is associated with a low inflammatory response, better hemostasis ${ }^{23-25}$. The biggest challenge has been the identification of a balance between reducing surgical trauma and ensuring viability. Several studies evaluated the inflammatory response to supply a laboratory substrate to correlate to clinical outcomes of minimally invasive surgery ${ }^{1,6-8}$. However, there is a lack of studies comparing singleport hysterectomy to traditional multiport laparoscopic hysterectomy.

In the current proposal, the reductions in the size and number (singleport) of ports are new modalities for laparoscopic surgery that the eventual reduction of surgical morbidity. However, both procedures had similar results. Singleport laparoscopic surgery is thought to be associated with less incidence of infections, epigastric vessel trauma, postoperative pain and incisional hernias than multiport laparoscopy ${ }^{20-26}$. Additionally, this approach allows an easier removal of the surgical specimen ${ }^{24}$.

In relation to inflammatory response, each cytokine reaches its peak value at different moments. Therefore, we measured the plasmatic levels of CPR, IL-6, IL-10, TNF- $\alpha$, VEGF and leucogram along the 6-postoperative days, building a detailed evaluation. The data in literature are low comparing the two techniques. In fact, a study evaluated the inflammatory responses of children 
who underwent single-port laparoscopic varicocelectomy with another with three-port laparoscopic procedures. They did not find any difference in terms of IL- 6 or TNF- $\alpha$ levels, which were measured one hour after the surgeries ${ }^{26-27}$.

In terms of IL-6 and VEGF, there were no significant differences between the groups. The highest levels of these inflammatory markers occurred on the first postoperative day as previously reported ${ }^{1,4}$. Evaluations of the average peak values of IL- 6 revealed that the results we observed were lower than those reported in a systematic review. ${ }^{1}$ Based on this observation, we believe that the inflammatory responses we verified in both groups were not sufficient to elevate the levels of IL-10, which is an anti-inflammatory cytokine. Additionally, the increase in IL-6 levels without an elevation of TNF- $\alpha$ may reflect the surgical trauma to the tissue in isolation with the absence of a significant systemic inflammatory response ${ }^{26}$. In our study, the TNF-aand IL-10 levels did not exhibit variation across the postoperative days, which suggests reduced inflammatory responses associated with both approaches.

During the singleport hysterectomy, we observed some surgical limitations, such as difficulty of instrumental triangulation, reduced visualization of abdominal cavity, and crowding and clashing of instruments. These difficulties led us to choose the vaginal approach to close the vaginal vault closure in 14 cases. For the same reasons, we were unable to perform the SP-TLH in a patient with severe pelvic adhesions. The main limitation of this study is the small cohort of patients.

\section{Conclusions}

Multiport and singleport laparoscopy are both feasible and safe approaches to hysterectomy with similar inflammatory response. We did not find any advantage by using the single-port approach to perform laparoscopic hysterectomy. Although the MPTLH operative time was significantly shorter than that of SP-TLH, the surgical time did not affect the inflammatory response intensity.

\section{References}

1. Watt DG, Horgan PG, McMillan DC. Routine clinical markers of the magnitude of the systemic inflammatory response after elective operation: a systematic review. Surgery. 2015; 157(2):362-80. doi: 10.1245/ s10434-017-5987-z.

2. Hoover L, Bochicchio GV, Napolitano LM, Joshi M, Bochicchio K, Meyer W, Scalea TM. Systemic inflammatory response syndrome and nosocomial infection in trauma. J Trauma. 2006;61(2):310-6. doi: 10.1097/01. ta.0000229052.75460.c2.

3. Dabrowska AM, Słotwiński R. The immune response to surgery and infection. Cent Eur J Immunol. 2014; 39(4):532-7. doi: 10.5114/ ceji.2014.47741.

4. Werner S, Grose R. Regulation of wound healing by growth factors and cytokines. Physiol Ver. 2003;83(3):835-70. doi: 10.1152/physrev.00031.2002.

5. Shiroma ME, Botelho NM, Damous LL, BaracatEC, Soares-JrJM. Melatonin influence in ovary transplantation: systematic review. J Ovarian Res. 2016;9(1):33. doi: 10.1186/ s13048-016-0245-8.

6. Ribeiro SC, Ribeiro RM, Santos NC, Pinotti JA. A randomized study of total abdominal, vaginal and laparoscopic hysterectomy. Int J Gynaecol Obstet. 2003; 83(1):37-43. PMID: 14511870.

7. Ellström M, Bengtsson A, Tylman M, Haeger $\mathrm{M}$, Olsson JH, Hahlin M. Evaluation of tissue trauma after laparoscopic and abdominal hysterectomy: measurements of neutrophil activation and release of interleukin-6, cortisol, and C-reactive protein. J Am Coll Surg. 1996;182(5):423-30. PMID: 8620278.

8. Labib M, Palfrey S, Paniagua E, Callender R. The postoperative inflammatory response to injury following laparoscopic assisted vaginal hysterectomy versus abdominal hysterectomy. Ann Clin Biochem. 1997;34:543-5. doi: 10.1177/000456329703400509. 
9. Kim TK, Yoon JR. Comparison of the neuroendocrine and inflammatory responses after laparoscopic and abdominal hysterectomy. Korean J Anesthesiol. 2010;59(4):265-9. doi: 10.4097/ kjae.2010.59.4.265.

10.Jackson T, Einarsson J. Single-port gynecologic surgery. Rev Obstet Gynecol. 2010;3(3):133-9.

11.Kim TJ, Lee YY, Cha $\mathrm{HH}$, Kim $\mathrm{CJ}$, Choi CH, Lee JW, Bae DS, Lee JH, Kim BG. Singleport-access laparoscopic-assisted vaginal hysterectomy versus conventional laparoscopic-assisted vaginal hysterectomy: a comparison of perioperative outcomes. Surg Endosc. 2010;24(9):2248-52. doi: 10.1007/s00464-010-0944-y.

12.Yim GW, Jung YW, Paek J, Lee SH, Kwon HY, Nam EJ, Kim S, Kim JH, Kim YT, Kim SW. Transumbilical single-port access versus conventional total laparoscopic hysterectomy: surgical outcomes. Am J Obstet Gynecol. 2010;203(1):26.e1-6. doi: 10.1016/j.ajog.2010.02.026.

13.Chen YJ, Wang PH, Ocampo EJ, Twu NF, Yen MS, Chao KC. Single-port compared with conventional laparoscopic-assisted vaginal hysterectomy: a randomized controlled trial. Obstet Gynecol. 2011;117(4):906-12. doi: 10.1097/AOG.0b013e31820c666a.

14.Li M, Han Y, Feng YC. Single-port laparoscopic hysterectomy versus conventional laparoscopic hysterectomy: a prospective randomized trial. J Int Med Res. 2012;40(2):701-8. doi: 10.1177/147323001204000234.

15.Wang T, Chong GO, Park NY, Hong DG, Lee YS. Comparison study of singleport (OctoportTM) and four-port total hysterectomy. Eur J Obstet Gynecol Reprod Biol. 2012;161(2):215-8. doi: 10.1016/j. ejogrb.2011.12.028.

16.Lee JH, Choi JS, Jeon SW, Son CE, Hong $\mathrm{JH}$, Bae JW. A prospective comparison of single-port laparoscopically assisted vaginal hysterectomy using transumbilical GelPort access and multiport laparoscopically assisted vaginal hysterectomy. Eur J Obstet Gynecol Reprod Biol. 2011;158(2):294-7. doi: 10.1016/j.ejogrb.2011.05.002.

17.Puntambekar S, Rayate N, Nadkarni A, Joshi S, Agrawal G, Desai R. Single-incision total laparoscopic hysterectomy with conventional laparoscopy ports. Int J Gynaecol Obstet. 2012;117(1):37-9. doi: 10.1016/j.ijgo.2011.11.021.

18.Jung $\mathrm{YW}$, Lee $M$, Yim GW, Lee $\mathrm{SH}$, Paek JH, Kwon HY, Nam EJ, Kim SW, Kim YT. A randomized prospective study of single-port and four-port approaches for hysterectomy in terms of postoperative pain. Surg Endosc. 2011;25(8):2462-9. doi: 10.1007/s00464010-1567-z.

19.Kadar N, Reich H, Liu CY, Manko GF, Gimpelson R. Incisional hernias after major laparoscopic gynecologic procedures. Am J Obstet Gynecol. 1993;168:1493-5. PMID: 8498433.

20.Tormena RA, Ribeiro SC, Maciel GA, Baracat EC. Single-port laparoscopic hysterectomy: preliminary results. Rev Assoc Med Bras. 2015;61(5):446-51. doi: 10.1590/18069282.61.05.446.

21.DeLoach LJ, Higgins MS, Caplan AB, Stiff JL. The visual analog scale in the immediate postoperative period: intrasubject variability and correlation with a numeric scale. Anesth Analg.1998;86(1):102-6. PMID: 9428860.

22. Olive DL, Parker WH, Cooper JM, Levine RL. The AAGL classification system for laparoscopic hysterectomy. Classification committee of the American Association of Gynecologic Laparoscopists. J Am Assoc Gynecol Laparosc. 2000;7(1):9-15. PMID: 10787274.

23. Einarsson JI, Matteson KA, Schulkin J, Chavan NR, Sangi-Haghpeykar H. Minimally invasive hysterectomies-a survey on attitudes and barriers among practicing gynecologists. J Minim Invasive Gynecol. 2010;17(2):167-75. doi: 10.1016/j.jmig.2009.12.017.

24.Escobar PF, Starks D, Fader AN, Catenacci M, Falcone T. Laparoendoscopic single-site and natural orifice surgery in gynecology. Fertil Steril. 2010;94(7):2497-502. doi: 10.1016/j. fertnstert.2010.08.018.

25.Caetano Júnior EM, Vieira JP, MouraFranco RM, Fuziy RA, Serra HO, Marcondes GB, Shiraiwa DK, Sousa MG, Girão MJ, Lopes-Filho GJ, Linhares MM. Evaluation of systemic inflammatory responses in cholecystectomy by means of access. Singleport umbilical incision, transvaginal NOTES, laparoscopy and laparotomy. Acta Cir Bras. 2015;30(10):691-703. doi: 10.1590/S010286502015010000000 . 
26. Hao W, Chan IH, Liu X, Tang PM, Tam PK, Wong KK. Early post-operative interleukin 6 and tumor necrosis factor- $\alpha$ levels after single-port laparoscopic varicocelectomy in children. Pediatr Surg Int. 2012;28(3):281-6. doi: 10.1007/s00383-011-3011-4.

27.Greco F, Hoda MR, Mohammed N, Springer
C, Fischer K, Fornara P. Laparoendoscopic single-site and conventional laparoscopic radical nephrectomy result in equivalent surgical trauma: preliminary results of a single-centre retrospective controlled study. Eur Urol. 2012;61(5):1048-53. doi: 10.1016/j.eururo.2012.01.043.

\section{Correspondence:}

José Maria Soares Júnior

Rua Alvorada, 64/114

04550-000 São Paulo - SP Brasil

Tel.: (55 11)3849-8390

r.tormena@uol.com.br

Received: Mar 23, 2017

Review: May 25, 2017

Accepted: June 26, 2017
Conflict of interest: none

Financial source: none
${ }^{1}$ Research performed at Division of Gynecology, Department of Obstetrics and Gynecology, School of Medicine, Hospital das Clínicas, Universidade de São Paulo (USP), Brazil. 